\title{
Geographic Variations of Three Fulvia mutica Populations
}

\author{
Seo-Kyeong Kang and Jong-Man Yoon \\ Department of Aquatic Life Medicine, College of Ocean Science and Technology, Kunsan National University, Gunsan \\ 573-701, Korea
}

\begin{abstract}
In the present study, the seven primers BION-33, BION-34, BION-37, BION-41, BION-44, BION-45 and BION-42 generated the total number of loci, average number of loci per lane and specific loci in Hongseong, Yeosu and Goheung population of F. mutica, respectively. 7 primers generated 19 specific loci in the Hongseong population, 29.3 in the Yeosu population and 23.1 in the Goheung population, respectively. Especially, the decamer primer BION-37 generated 7 unique loci to each population, which were identifying each population, approximately 700 bp in Hongseong population. In this study, the dendrogram obtained by the seven primers indicates three genetic clusters: cluster 1 (HONGSEONG 01-HONGSEONG 07), cluster 2 (YEOSU 08-YEOSU 14) and cluster 3 (GOHEUNG 15-GOHEUNG 21). Among the twenty one cockles, the shortest genetic distance that displayed significant molecular differences was between individuals 17 and 19 from the Goheung population (genetic distance $=0.051$ ), while the longest genetic distance among the twenty-one cockle individuals that displayed significant molecular differences was between individuals HONGSEONG no. 03 and YEOSU no. 12 (genetic distance $=0.616$ ). Relatively, individuals of YEOSU population were fairly closely related to that of GOHEUNG population. Ultimately, PCR fragments revealed of in this study may be useful as a DNA marker the three geographic populations to distinguish.
\end{abstract}

Key words: Cockles, Fulvia mutica, Genetic distance, Geographic variations, Specific loci

\section{INTRODUCTION}

Fulvia mutica is, ecologically warmwater bivalve species, belonging to the class Bivalvia, and family Cardiidae, widely distributed on the coast of the Yellow Sea, southern sea and Jeju Island in the Korean peninsula and the several sea areas in Japan and China under the natural ecosystem. The cockles dwell in a sandy mud bottom consisting of a lot of sand, mud and slime from 10 to $50 \mathrm{~m}$ in depth. The breeding seasons are February to June, and August to

Received: September 11, 2013; Accepted: September 25, 2013

Corresponding author : Jong-Man Yoon

Tel: +82 (63) 469-1887 e-mail: jmyoon@kunsan.ac.kr

$1225-3480 / 24483$

This is an Open Access article distributed under the terms of the Creative Commons Attribution Non-Commercial License with permits unrestricted non-commercial use, distribution, and reproducibility in any medium, provided the original work is properly cited.
November. The name is from their fairly long inner feet that look like beaks of birds when they are peeled. The cockles are yellowish brown and coarse in the shell surface, and the inside is pink under natural conditions. There are 40-50 thin and slim radial-shaped wrinkles on surfaces. Shell surface is covered with light brown epidermis, and the inside is pink. Inner feet are long, triangular, and dark brown. Basically, there are marked differences of the size, color and shape in $F$. mutica according to the environmental conditions of habitat such as feed and winterization period. However, these kinds of Korean bivalve, which are recognized important physiologically (Yang, 2006), biochemically (Mahmoud et al., 2010) as well as economically (Kim et al., 2001), are not genetically studied or researched like other shellfishes. There is a need to understand the genetic traits and composition of this bivalve in order to evaluate exactly the patent genetic effect. We perform clustering analyses to elucidate the genetic distances and 


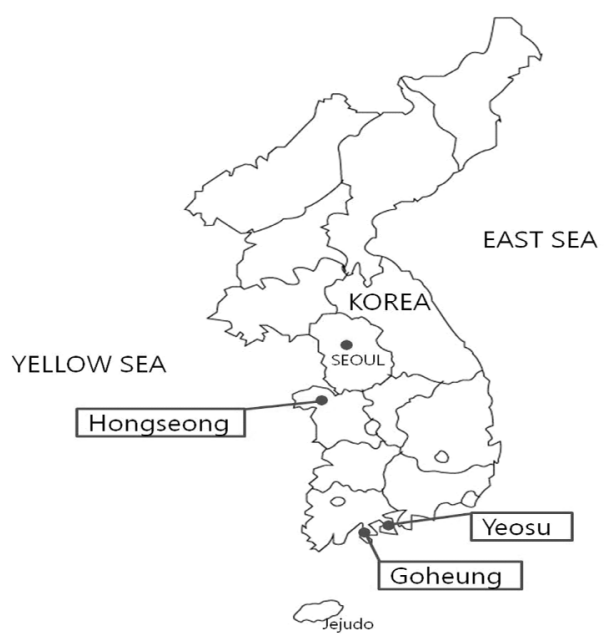

Fig.1. Map illustrating bivalve sampling localities. Genomic DNA samples isolated from three geographical F. mutica populations collected in Hongseong of the Yellow Sea, Yeosu and Goheung of the southern sea, off the Korean Peninsula.

geological variations among three Fulvia mutica geographical populations from Hongseong, Yeosu and Goheung of the Korean peninsula, using PCR method.

\section{MATERIALS AND METHODS}

\section{Sample collection and purification of genomic DNA}

Three geographic populations of the $F$. mutica were obtained from three different regions of Hongseong, Yeosu and Goheung in Korea, respectively, as shown in Fig. 1. Cockle muscle was collected in sterile tubes, placed on ice immediately, and stored at - $40^{\circ} \mathrm{C}$ until needed. PCR analysis was performed on DNA samples extracted from a total of 21 individuals using seven decamer primers. DNA extraction/purification should be carried out according to the methods previously described (Yoon and Kim, 2004). The DNA pellets were incubation-dried for $2 \mathrm{hrs}$, held at $-40^{\circ} \mathrm{C}$ until analysis, and then dissolved in the TE buffer $(10 \mathrm{mM}$ Tris- $\mathrm{HCl}$, $\mathrm{pH}$ 8.0; $1 \mathrm{mM}$ EDTA). The concentrations of the extracted genomic DNA samples were estimated based on the absorbance at $260 \mathrm{~nm}$ by a spectrophotometer (Beckman Coulter, Buckinghamshire, UK).

\section{Amplification conditions and data analyses}

We used the decamer primers to clarify the genetic distances and geological variations of $F$. mutica individuals. Seven primers, BION-33 (5'-ACATCCTGCG3'), BION-34 (5'-GCCGCTACTA-3'), BION-37 (5'-AGTCAGCCAC-3'), BION-41 (5'-ATCGGGTCCG-3'), BION-44 (5'-TGCCGAGCTG-3'), BION-45 (5'-CAAACGTCGG-3'), and BION-42 (5'-TACGATGACG3 ') were shown to generate the unique shared loci to each population and shared loci by the three $F$. mutica populations which could be clearly scored. Thus, we used the primers to study the genetic variations and DNA polymorphisms of the cockle. PCR was performed using Programmable DNA Thermal Cycler (MJ Research Inc., Waltham, MA, USA). Optimal DNA concentrations for amplification were determined by testing several dilutions, one of which was taken as the standard for every subsequent amplification. Amplification products were separated by electrophoresis in $1.4 \%$ agarose gels (Bioneer Corp., Daejeon, Korea) with TBE (0.09 M Tris, pH 8.5; 0.09 M borate; $2.5 \mathrm{mM}$ EDTA). The 100 bp DNA ladder (Bioneer Corp., Daejeon, Korea) was used as a DNA molecular weight marker. The electrophoresed agarose gels were illuminated by ultraviolet rays, and photographed using a Photoman direct copy system (PECA Products, Beloit, WI, USA).

Bandsharing (BS) values were calculating according to the presence/absence of amplified products at specific positions in the same gel from the PCR profiles. Absence of bands indicates that the priming site is not present, presumably as a result of some alteration in the DNA sequence. The degree of variableness was calculated by use of the Dice coefficient $(F)$, which is given by the formula: $F(\mathrm{BS})=$ $2 \mathrm{n}_{\mathrm{ab}} /\left(\mathrm{n}_{\mathrm{a}}+\mathrm{n}_{\mathrm{b}}\right)$, where $\mathrm{n}_{\mathrm{ab}}$ is the number of bands shared between the samples a and $b, n_{a}$ is the total number of bands for sample $\mathrm{a}$ and $\mathrm{n}_{\mathrm{b}}$ is the total number of bands for sample b (Jeffreys and Morton, 1987; Yoke-Kqueen and Radu, 2006). The average within-population similarity was calculated by pairwise comparison between individuals within a population. The levels of relatedness among different individuals from Hongseong population (HONGSEONG 01-HONGSEONG 07), Yeosu population (YEOSU 08YEOSU 14) and Goheung population (GOHEUNG 15-GOHEUNG 21) were generated according to the 


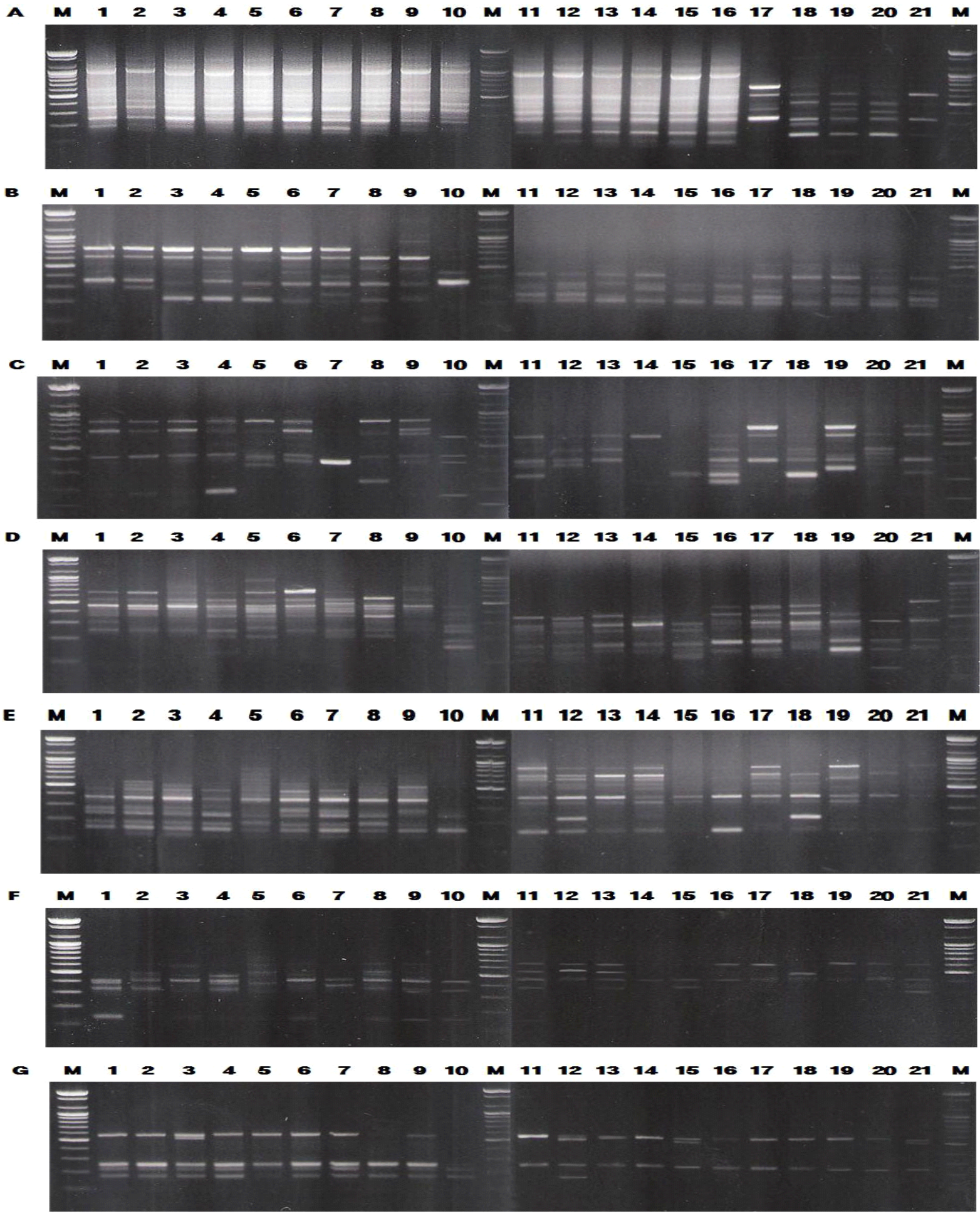

Fig. 2. PCR-based electrophoretic profiles of individuals $F$. mutica. Each lane shows DNA samples extracted from 21 individuals. The DNA isolated from Hongseong population (lane 1-7), Yeosu population (lane 8-14) and Goheung population of F. mutica (lane 15-21) were amplified by decamer primers BION-33 (A), BION-34 (B), BION-37 (C), BION-41 (D), BION-44 (E), BION-45 (F) and BION-42(G). The PCR products were separated by $1.4 \%$ agarose gel electrophoresis, and stained with ethidium bromide. $100 \mathrm{bp}$ ladder (M) was used as a DNA molecular weight marker. 
Table 1. Similarity matrix including bandsharing values (BS) and genetic differences calculated using Nei and Li's index of the similarity of $F$. mutica from Hongseong, Yeosu and Goheung of Korea, respectively

\begin{tabular}{|c|c|c|c|c|c|c|c|c|c|c|c|c|c|c|c|c|c|c|c|c|c|}
\hline & \multicolumn{7}{|c|}{ BS from Hongseong } & \multicolumn{7}{|c|}{ BS from Yeosu } & \multicolumn{7}{|c|}{ BS from Goheung } \\
\hline & 1 & 2 & 3 & 4 & 5 & 6 & 7 & 8 & 9 & 10 & 11 & 12 & 13 & 14 & 15 & 16 & 17 & 18 & 19 & 20 & 21 \\
\hline 1 & - & 0.890 & 0.894 & 0.854 & 0.796 & 0.825 & 0.835 & 0.712 & 0.718 & 0.656 & 0.535 & 0.611 & 0.591 & 0.532 & 0.581 & 0.482 & 0.384 & 0.505 & 0.462 & 0.411 & 0.406 \\
\hline 2 & & - & 0.815 & 0.783 & 0.742 & 0.863 & 0.752 & 0.722 & 0.702 & 0.673 & 0.600 & 0.693 & 0.624 & 0.636 & 0.611 & 0.510 & 0.410 & 0.576 & 0.428 & 0.390 & 0.410 \\
\hline 3 & & & - & 0.820 & 0.800 & 0.832 & 0.813 & 0.710 & 0.710 & 0.645 & 0.544 & 0.672 & 0.600 & 0.530 & 0.526 & 0.543 & 0.508 & 0.549 & 0.526 & 0.480 & 0.526 \\
\hline 4 & & & & - & 0.768 & 0.760 & 0.742 & 0.666 & 0.682 & 0.698 & 0.444 & 0.541 & 0.471 & 0.460 & 0.477 & 0.417 & 0.406 & 0.468 & 0.407 & 0.359 & 0.385 \\
\hline 5 & & & & & - & 0.846 & 0.776 & 0.749 & 0.751 & 0.595 & 0.610 & 0.678 & 0.626 & 0.559 & 0.468 & 0.538 & 0.534 & 0.590 & 0.494 & 0.533 & 0.465 \\
\hline 6 & & & & & & - & 0.876 & 0.782 & 0.764 & 0.618 & 0.618 & 0.707 & 0.665 & 0.596 & 0.492 & 0.585 & 0.511 & 0.604 & 0.534 & 0.470 & 0.459 \\
\hline 7 & & & & & & & - & 0.740 & 0.734 & 0.619 & 0.564 & 0.621 & 0.528 & 0.513 & 0.499 & 0.504 & 0.479 & 0.532 & 0.523 & 0.432 & 0.474 \\
\hline 8 & & & & & & & & - & 0.725 & 0.623 & 0.552 & 0.790 & 0.557 & 0.497 & 0.527 & 0.496 & 0.418 & 0.503 & 0.493 & 0.419 & 0.359 \\
\hline 9 & & & & & & & & & - & 0.625 & 0.558 & 0.637 & 0.538 & 0.487 & 0.440 & 0.406 & 0.373 & 0.498 & 0.400 & 0.440 & 0.357 \\
\hline 10 & & & & & & & & & & - & 0.459 & 0.518 & 0.499 & 0.479 & 0.472 & 0.383 & 0.300 & 0.395 & 0.346 & 0.384 & 0.381 \\
\hline 11 & & & & & & & & & & & - & 0.832 & 0.827 & 0.701 & 0.558 & 0.692 & 0.580 & 0.598 & 0.594 & 0.527 & 0.546 \\
\hline 12 & & & & & & & & & & & & - & 0.821 & 0.734 & 0.528 & 0.672 & 0.634 & 0.604 & 0.617 & 0.567 & 0.528 \\
\hline 13 & & & & & & & & & & & & & - & 0.800 & 0.604 & 0.671 & 0.583 & 0.619 & 0.535 & 0.559 & 0.553 \\
\hline 14 & & & & & & & & & & & & & & . & 0.629 & 0.621 & 0.563 & 0.598 & 0.562 & 0.512 & 0.471 \\
\hline 15 & & & & & & & & & & & & & & & & 0.640 & 0.503 & 0.522 & 0.495 & 0.457 & 0.628 \\
\hline 16 & & & & & & & & & & & & & & & & - & 0.771 & 0.682 & 0.750 & 0.689 & 0.669 \\
\hline 17 & & & & & & & & & & & & & & & & & - & 0.725 & 0.852 & 0.772 & 0.678 \\
\hline 18 & & & & & & & & & & & & & & & & & & - & 0.677 & 0.657 & 0.573 \\
\hline 19 & & & & & & & & & & & & & & & & & & & - & 0.776 & 0.683 \\
\hline 20 & & & & & & & & & & & & & & & & & & & & - & 0.697 \\
\hline 21 & & & & & & & & & & & & & & & & & & & & & - \\
\hline
\end{tabular}

bandsharing values and similarity matrix. A hierarchical clustering tree was assembling using similarity matrices to produce a dendrogram, which was facilitated by the Systat version 10 software (SPSS Inc., Chicago, IL, USA). The Systat software was also used to analyze genetic differences, Euclidean genetic distances within and between populations, means, standard errors, and t-test scores.

\section{RESULTS AND DISCUSSION}

The amplified products were separated by agarose gel electrophoresis (AGE) with oligonucleotides decamer primers, and stained with ethidium bromide. Similarity matrix including bandsharing values (BS) and genetic differences was calculated using Nei and Li's index of the similarity of cockle individuals from Hongseong, Yeosu and Goheung of the Korean peninsula, respectively, as illustrated in Table 1. The seven selected primers BION-33, BION-34, BION-37, BION-41, BION-44, BION-45 and BION-42 generated the total number of loci, average number of loci per lane and specific loci in Hongseong, Yeosu and
Goheung population, as summarized in Table 2. Here, the complexity of the banding patterns varied dramatically between the primers from the three locations. The size of the DNA fragments also varied wildly, from 100 to $1,600 \mathrm{bp}$, as shown in Fig. 1. The primer BION-33 generated the most loci (a total of 70), with an average of 10.0 in the Yeosu population, as illustrated in Table 2. The decamer primer BION-45 generated the least loci (a total of 15), with an average of 2.14 in the Goheung population, in comparison to the other primers used. In the present study, 7 primers generated 19 specific loci in the Hongseong population, 29.3 in the Yeosu population and 23.1 in the Goheung population. The specific loci generated by decamer primers exhibited inter-individual-specific characteristics, thus revealing DNA polymorphisms. Many researchers studied the sizes of DNA fragments in the PCR profiles of five species of Eastern Pacific abalone (genus Haliotis) (Muchmore et al., 1998), black tiger shrimp (Penaeus monodon) (Tassanakajon et al., 1998), the brittle star (Amphiura filiformis) (McCormack et al., 2000), marsh clams (Corbicula spp.) (Yoon and Kim, 2003a) and shrimp populations (Yoon 
Table 2. The number of average loci per lane and specific loci by PCR analysis using 7 primers in F. mutica in Hongseong, Yeosu and Goheung of Korea

\begin{tabular}{|c|c|c|c|c|c|c|}
\hline \multirow{2}{*}{$\begin{array}{c}\text { Item } \\
\text { Primer }\end{array}$} & \multicolumn{3}{|c|}{ No. of average loci per lane } & \multicolumn{3}{|c|}{ No. of specific loci } \\
\hline & HS & YS & GH & HS & YS & $\mathrm{GH}$ \\
\hline BION-33 & $9.86(69)$ & $10.0(70)$ & $7.43(52)$ & 13 & 14 & 31 \\
\hline BION-34 & $6.29(44)$ & $5.29(37)$ & $5.43(38)$ & 23 & 37 & 31 \\
\hline BION-37 & $4.14(29)$ & $4.00(28)$ & $4.86(34)$ & 22 & 28 & 34 \\
\hline BION-41 & $9.14(64)$ & $7.00(49)$ & $5.71(40)$ & 15 & 35 & 33 \\
\hline $\mathrm{BION}-44$ & $7.86(55)$ & $8.43(59)$ & $5.29(37)$ & 27 & 52 & 23 \\
\hline $\mathrm{BION}-45$ & $5.71(40)$ & $3.86(27)$ & $2.14(15)$ & 26 & 20 & 8 \\
\hline BION-42 & $6.00(42)$ & $3.71(26)$ & $2.29(16)$ & 7 & 19 & 2 \\
\hline Total No. & $49(343)$ & $42.3(296)$ & $33.1(232)$ & 133 & 205 & 162 \\
\hline $\begin{array}{l}\text { Average No. per } \\
\text { primer }\end{array}$ & 49 & 42.3 & 33.1 & 19 & 29.3 & 23.1 \\
\hline
\end{tabular}

The total number of loci generated by 7 primers in F. mutica obtained from Hongseong, Yeosu and Goheung is shown in parentheses. HS: Hongseong, YS: Yeosu, GH: Goheung

Table 3. The number of unique loci to each population and number of shared loci by the three populations generated by PCR analysis using 7 decamer primers in Hongseong, Yeosu and Goheung population of $F$. mutica, respectively

\begin{tabular}{ccccc}
\hline Item & No. of unique loci to each population & $\begin{array}{c}\text { No. of shared loci by the three } \\
\text { populations }\end{array}$ \\
\hline Primer $\backslash$ Population & Hongseong & Yeosu & Goheung & $\begin{array}{c}\text { Three populations } \\
\text { (7 individuals per population) }\end{array}$ \\
\hline BION - 33 & 56 & 56 & 21 & 42 \\
BION - 34 & 21 & 0 & 7 & 0 \\
BION - 37 & 7 & 0 & 0 & 0 \\
BION - 41 & 42 & 14 & 7 & 0 \\
BION - 44 & 28 & 7 & 14 & 21 \\
BION - 45 & 14 & 7 & 7 & 21 \\
BION - 42 & 35 & 7 & 14 & 105 \\
\hline Total no. & 203 & 91 & 70 & 15 \\
\hline Average no. per primer & 29 & 13 & 10 & \\
\hline
\end{tabular}

and Kim, 2003b).

The seven selected primers BION-33, BION-34, BION-37, BION-41, BION-44, BION-45 and BION-42 were used to generate unique shared loci to each population and shared loci by the four populations, as summarized in Table 3. The decamer primer BION-33 generated 56 unique loci to each population, approximately 250 bp, 350 bp, 500 bp, 600 bp, 700 bp, $1000 \mathrm{bp}, 1200 \mathrm{bp}$ and $1600 \mathrm{bp}$, respectively, in the Hongseong population. Especially, the decamer primer BION-37 generated 7 unique loci to each population, which were identifying each population, approximately $700 \mathrm{bp}$ in Hongseong population, as summarized in
Table 3. Interestingly, the primer BION-33 detected 42 shared loci by the three populations, major and/or minor fragments of sizes $350 \mathrm{bp}$ and $600 \mathrm{bp}$, respectively, which were identical in all samples. As regards average bandsharing value (BS) results, individuals from Hongseong population (0.813) exhibited higher bandsharing values than did individuals from Yeosu population (0.631), as summarized in Table 4. In this study, the dendrogram obtained by the seven decamer primers indicates three genetic clusters: cluster 1 (HONGSEONG 01HONGSEONG 07), cluster 2 (YEOSU 08-YEOSU 14) and cluster 3 (GOHEUNG 15-GOHEUNG 21). Among 
Table 4. Multiple comparisons of average bandsharing values among Korean F. mutica populations from three regions were generated according to the bandsharing values and similarity matrix

\begin{tabular}{cccc}
\hline Population & Hongseong & Yeosu & Goheung \\
\hline Hongseong & 0.813 & 0.633 & 0.487 \\
Yeosu & - & 0.631 & 0.513 \\
Goheung & - & - & 0.662 \\
\hline
\end{tabular}

the twenty-one cockle, the shortest genetic distance that displayed significant molecular differences was between individuals 17 and 19 from the Goheung population (genetic distance $=0.051$ ), while the longest genetic distance among the twenty-one $F$. mutica individuals that demonstrate $d$ significant molecular differences was between individuals HONGSEONG no. 03 and YEOSU no. 12 (genetic distance $=0.616$ ). Relatively, individuals of YEOSU population were fairly closely related to that of GOHEUNG population. From what has been said above, a dendrogram disclosed close relationships between individual characteristics within three geographical bivalve populations (McCormack et al., 2000). In invertebrates, cluster analysis of the pairwise population matrix, generated from genetic data, showed that geographically close populations be inclined to cluster together in the blacklip abalone (Huang et al., 2000).

Cluster Tree

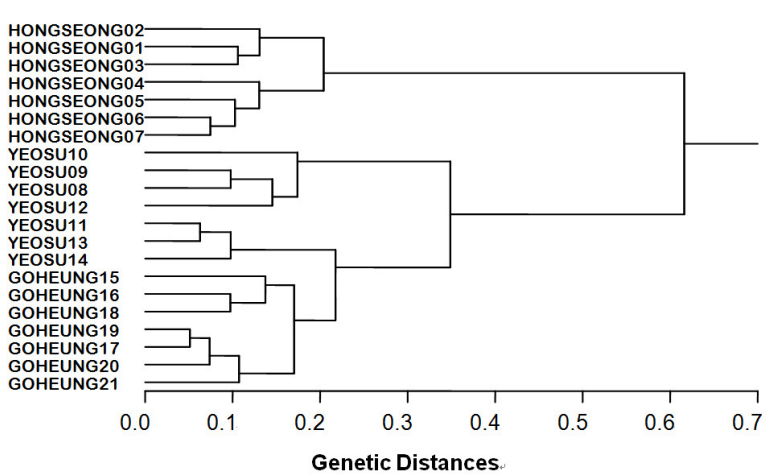

Fig. 3. Hierarchical dendrogram of genetic distances, obtained from three populations of F. mutica. The relatedness among different individuals in the three cockle populations from Hongseong, Yeosu and Goheung of the Korean peninsula were generated according to the bandsharing values and similarity matrix.
Above-mentioned, a dendrogram disclosed close relationships between individual identities within three geographical bivalve populations (McCormack et al., 2000). Three F. mutica populations can be clearly distinguished, by PCR-based approach. The potential of oligonucleotides amplified polymorphic DNAs to discover diagnostic markers for breed, species and population identification in shellfish (McCormack et al., 2000; Kim et al., 2004; Park et al., 2005) has also been well established. PCR fragments discovered of in this study may be useful as a DNA marker the three regional populations to distinguish. In general, the population classification of $F$. mutica is founded on morphological variations in shell body weight, shell type, shell color, shell length and feet length. It is implicated that differences in such characters reflect distinctive origins or genetic identity (Chenyambuga et $a l ., 2004)$. If Korean F. mutica systematic study was in supplemental progress, which could be utilized as fundamental data.

\section{ACKNOWLEDGEMENTS}

Our authors would like to thank anonymous referees who assisted with detailed and considerate correction. Particular thanks also go to our laboratory colleagues, for their assistance in sample collection, DNA extraction/purification, electrophoresis, and their help with PCR techniques.

\section{REFERENCES}

Chenyambuga, S.W., Hanotte, O., Hirbo, J., Watts, P.C., Kemp, S.J., Kifaro, G.C., Gwakisa, P.S., Petersen, P.H. and Rege, J.E.O. (2004) Genetic characterization of indigenous goats of sub-Saharan Africa using microsatellite DNA markers. Asian-Australasian Journal of Animal Sciences, 17: 445-452.

Huang, B.X., Peakall, R. and Hanna, P.J. (2000) Analysis of genetic structure of blacklip abalone 
(Haliotis rubra) populations using RAPD, minisatellite and microsatellite markers. Marine Biology, 136: 207-216.

Jeffreys, A.J. and Morton D.B. (1987) DNA fingerprints of dogs and cats. Animal Genetics, 18: 1-15.

Kim, Y.H., Chang, D.S., Cha, B.R. and Park, Y.C. (2001) Estimation of population size of Fulvia mutica (Reeve) in Gwangyang Bay. Abstracts 2001 Joint Meeting of the Korean Society on Fisheries Science: 400-401 (in Korean).

Kim, J.Y, Park, C.Y. and Yoon, J.M. (2004) Genetic differences and DNA polymorphism in oyster (Crassostrea spp.) analysed by RAPD-PCR. Korean Journal of Genetics, 26: 123-134.

Mahmoud, N., Dellali, M., El Bour, M., Aissa, P. and Mahmoudi, E. (2010) The use of Fulvia fragilis (Mollusca: Cardiidae) in the biomonitoring of Bizerta lagoon: A multimarkers approach. Ecological Indicators, 10: 696-701.

McCormack, G. C., Powell, R and Keegan, B. (2000) Comparative analysis of two populations of the brittle star Amphiura filiformis (Echinodermata: Ophiuroidae) with different life history strategies using RAPD markers. Marine Biotechnology, 2: 100-106.

Muchmore, M.E., Moy, G.W., Swanson, W.J. and Vacquier, V.D. (1998) Direct sequencing of genomic DNA for characterization of a satellite DNA in five species of Eastern Pacific abalone. Molecular Marine Biology and Biotechnology, 7(1): 1-6.

Park, S.Y., Park, J.S. and Yoon, J.M. (2005) Genetic difference and variation in slipper lobster (Ibacus ciliatus) and deep sea lobster (Puerulus sewelli) throughout its distribution range determined by RAPD-PCR Analysis. Korean Journal of Genetics, 27: 307-317, 2005.

Tassanakajon, A., Pongsomboon, S., Jarayabhand, P., Klinbunga, S. and Boonsaeng, V. (1998) Genetic structure in wild populations of black tiger shrimp (Penaeus monodon) using randomly amplified polymorphic DNA analysis. Journal of Marine Biotechnology, 6: 249-254.

Yang, H.S. (2006) Reproductive cycle and proximate tissue composition of the cockle, Fulvia mutica from Anmyeon Island, on the west coast of Korea. Master thesis pp1-37.

Yoon, J.M. and Kim, Y.H. (2003a) Wide marsh clam (Corbicula spp.) populations from three sites analysed by RAPD-PCR-AGE. Bulletin of Electrochemistry, 19: 337-348.

Yoon, J.M. and Kim, G.W. (2003b) Genetic differences between cultured and wild penaeid shrimp (Penaeus chinensis) populations analysed by RAPD-PCR. Korean Journal of Genetics, 25: 21-32.

Yoon, J.M. and Kim, J.Y. (2004) Genetic differences within and between populations of Korean catfish ( $S$. asotus) and bullhead (P. fulvidraco) analyzed by RAPD-PCR. Asian-Australasian Journal of Animal Sciences, 17: 1053-1061.

Yoke-Kqueen, C. and Radu, S. (2006) Random amplified polymorphic DNA analysis of genetically modified organisms. Journal of Biotechnology, 127: 161-166. 